\title{
Cash Transfers, Basic Income and Community Building
}

\author{
Evelyn L. Forget*, Alexander D. Peden and Stephenson B. Strobel \\ Faculty of Medicine, University of Manitoba, 750 Bannatyne Ave., Winnipeg R3E 0W3, Canada; \\ E-Mails: evelyn.forget@med.umanitoba.ca (E.L.F.); umpedena@cc.umanitoba.ca (A.D.P.); \\ umstrobs@cc.umanitoba.ca (S.B.S.); Tel.: +1 2047893772 (E.L.F.); Fax: +1 2047893905 (E.L.F.) \\ * Corresponding author
}

Submitted: 29 July 2013 | In revised form: 29 August 2013 | Accepted: 31 August 2013 |

Published: 6 September 2013

\begin{abstract}
The austerity movement in high-income countries of Europe and North America has renewed calls for a guaranteed Basic Income. At the same time, conditional and unconditional cash transfers accompanied by rigorous impact evaluations have been conducted in low- and middle-income countries with the explicit support of the World Bank. Both Basic Income and cash transfer programs are more confidently designed when based on empirical evidence and social theory that explain how and why cash transfers to citizens are effective ways of encouraging investment in human capital through health and education spending. Are conditional cash transfers more effective and/or more efficient than unconditional transfers? Are means-tested transfers effective? This essay draws explicit parallels between Basic Income and unconditional cash transfers, and demonstrates that cash transfers to citizens work in remarkably similar ways in low-, middle- and high-income countries. It addresses the theoretical foundation of cash transfers. Of the four theories discussed, three explicitly acknowledge the interdependence of society and are based, in increasingly complex ways, on ideas of social inclusion. Only if we have an understanding of how cash transfers affect decision-making can we address questions of how best to design cash transfer schemes.
\end{abstract}

Keywords: basic income; conditional cash transfer; guaranteed annual income; negative income tax; social inclusion; unconditional cash transfer

\section{Introduction}

On 15 April 2013, the lower house of the Italian Parliament received more than 50,000 signatures that had been gathered in support of a popular initiative regarding/for a guaranteed minimum income in Italy [1]. In January 2013, a European Citizens' Initiative for an unconditional Basic Income (BI) was registered, and fifteen EU states are involved in the campaign to raise one million signatures before 14 January 2014. On 1 February 2013, a campaign to introduce an unconditional BI was launched in Finland. The Alaska Permanent Fund, financed by state oil revenue, has granted dividends to all state residents since 1976, and more 
recently state Senator Chip Shields introduced a proposal for a similar dividend scheme in Oregon [2]. The justification for many of these proposals rests explicitly on ideas of social inclusion, such as the European Parliament Resolution of 20 October 2010 on the Role of minimum income in combating poverty and promoting an inclusive society in Europe (2010/2039 (INI)) [2]. Similar themes resonate elsewhere. In Canada, for example, Senator Hugh Segal has invoked social inclusivity as a justification for a BI:

Being poor would become a problem we all buffered in the same way as we buffer all Canadians relative to health care. Only a small portion of Canadians needs expensive health care at any one time. But we are there to help as members of a competitive, free market and coherent society-not by embarrassing them with governments asking why they are sick, but by letting their universal health coverage, financed by general revenue, see them through [3].

This international movement builds on a long history. Between 1968 and 1980, five negative income tax experiments were conducted in North America with strong support from many of the leading economists of the period, to determine what impact, if any, a means-tested BI might have on the labor market [4]. A negative income tax, or refundable tax credit, is a specific form of means-tested BI.

The BI movement has received new vigour from two sources. The growing austerity movement in Europe and North America has led to criticism from social justice advocates and social policy analysts who can measure the negative impact of budget cuts on health and well-being [5]. Ironically, at a time when social expenditure in rich countries is being constrained and the negative social consequences becoming increasingly apparent, the World Bank is advocating cash transfers (CTs) to citizens of low- and middle-income countries as a means of reaching development goals. CT programs come in two flavours: conditional cash transfers (CCTs) in which recipients receive cash only if they can demonstrate that their behaviour meets certain stated requirements, and unconditional cash transfers (UCTs) in which the payout, in the spirit of a $\mathrm{BI}$, does not depend on individual behaviour.

Both BI and CT experiments have demonstrated that people who receive transfers tend to behave in ways that improves their well-being, as we demonstrate. More children are educated for longer periods of time. Health improves, partly as a consequence of behaviours such as reducing risky behaviour and increasing vaccination rates. However, neither the BI movement nor the CT movement has developed a very convincing theory about how and why these programs improve well-being.

This essay draws an explicit parallel between BI and CTs, and investigates how these schemes achieve beneficial outcomes. Section 2 examines CT schemes, examining whether it is the condition or the cash which is responsible for beneficial outcomes. Section 3 discusses parallel findings from a Canadian social experiment known as MINCOME, demonstrating that CTs function in remarkably similar ways in highincome countries, to how they do in low- and middleincome countries. Section 4 attempts to explain how CTs work. Of the four theories discussed, three explicitly acknowledge the interdependence of society and are based, in increasingly complex ways, on ideas of social inclusion. Only if we have an understanding of how CTs affect decision-making can we address questions of how best to design CTs. Section 5 acknowledges gaps in our knowledge, and maps a way forward.

\section{The Evidence from Conditional and Unconditional Cash Transfers}

The two types of CT programs delivered in low- and middle-income countries give us some insight into how these programs are perceived to work by those who propose them. The World Bank, which has offered strong support for CCTs, focuses on "incentives" and incentivizing desired behaviour. The argument is straightforward: if you want someone to behave in a particular way, the incentives must be such that the individual is rewarded for complying. In that spirit, a World Bank website claims:

Conditional cash transfers are an increasingly popular strategy for poverty reduction programs. The idea behind it is simple-money is provided to households that meet specific conditions. In other words, for a household to receive a cash transfer they must undertake certain activities, such as taking children for regular health check-ups and sending them to school [6].

If incentives are the answer to encouraging correct behaviour, the implication seems to be that too little of the desired behaviour would exist without incentives. Yet the incentivized behaviour is, or so the empirical evidence seems to suggest, beneficial to the individuals and families involved. If people need to be incentivized to act in their own best interests, then it must be the case that they behave otherwise largely because they are unaware of their own best interests. Part of the justification for CCTs, then, is to demonstrate the rewards that would accrue to recipients from incentivized behaviour.

Advocates of UCTs, such as OXFAM and UNICEF among others, have a very different implicit model in mind. They acknowledge the obvious: poverty is associated with behaviours harmful to individuals and families. Children (particularly girls) attend school less and for fewer years, family nutrition tends to be worse, vaccination rates are usually low, marriages and childbearing often occur before an age consistent with optimal health for mother and baby, and risky behaviour such as sex work is more prevalent than among better off households $[7,8]$. 
The solution, however, lies less in creating incentives that reward behaviour consistent with desired development goals than in making resources available to individual households so that they can make decisions consistent with their own priorities. This approach is based on a trust that individuals and families (acknowledging the different interests that sometimes exist within the family) know better than the programme designers what kind of behaviour is in their best interests. UCTs are preferred by human rights advocates and are consistent with rights-based approaches to development [7].

Beyond this easy dichotomy, however, some empirical evidence has emerged from the various CT schemes that can tell us more about how they work. Both CCTs and UCTs are consistent with positive outcomes-more children tend to be vaccinated, people eat better, more girls are educated and fewer marry early when one compares recipients of either CT programme to a control group that receives no CT at all [8-11]. Determining whether it is the cash or the condition - the additional resources or the incentivethat is responsible for positive outcomes is made difficult by the fact that most of the CCTs were introduced in Latin America, and most of the UCTs were implemented in Africa.

However, one of the best of these schemes was conducted in Zomba province, Malawi [9]. This was the first experiment explicitly designed to distinguish between the effects of the cash itself and the behavioural conditions imposed on families. Randomized at the level of the enumeration area, which contained several villages, three groups were constructed-one that received CCTs if their adolescent daughters attended school, a second that received UCTs and a third that acted as the control group and received no cash. Both the CCT and the UCT arm showed increased school attendance, with the CCT arm marginally more efficient at eliciting the incentivized behaviour. However, learning outcomes were not different between the two groups that received cash transfers. Moreover, the UCT arm reduced early marriages, early births and HIV transmission to a greater extent than did the CCT. That is, the CCT seemed to better elicit the incentivized behaviour-the condition-but to be less effective at eliciting other desired outcomes, an outcome replicated in Zimbabwe [10].

The Malawi researchers explain this outcome by noting that the initial conditions of the families were not identical. For the poorest and most vulnerable, the incentive offered to educate their adolescent daughters was not sufficient for the families to make that decision. When these families in the CCT arm did not comply, they received no funding at all. Abandoned by the programme, these girls were as vulnerable to early marriages and births, and to increased involvement in sex work as were those in the control group who received no funding from the outset. Similarly vulnerable families in the UCT arm, however, also chose not to educate their daughters but they still received the cash transfer because they were not compelled to comply with the condition. As a consequence, these families may have been able to better protect their daughters and keep them at home longer, even if they chose not to send them to school. UCTs allowed the poorest and most vulnerable to still receive some benefits and to allocate the money as they deem best-even if that allocation is not incentivized and not the preferred outcome of the programme designers.

A second apparently anomalous consideration was discussed in the Malawi study [9]. Researchers were concerned that they may have underestimated the impact of conditionality because of "contamination". Enumeration areas are small and people talk to one another raising the possibility that the behaviour of people in the UCT arm may have been influenced by the conditions imposed on those in the CCT arm. The researchers suggested that UCT families may have misunderstood their situation. That is, they may have chosen to educate their daughters because they mistakenly believed that they would otherwise not receive the cash transfer. Researchers contrived a test of this hypothesis: they noted that payments were made at arbitrary places designed for the convenience of the researchers. People from the various arms of the experiment received their transfers in the same place. If "contamination" were to have occurred, they suggest, it should have been greatest among those UCT families that interacted with CCT families at the payment site. They found no such evidence.

If one were to change the language - to replace "contamination" with "social interaction"-one might have designed the test differently and generated different outcomes. It is not inconceivable, for example, that a family may be more influenced by "cousins" in the CCT arm than by arbitrary interaction at the payment site. Moreover, the interaction may have led to a change in behaviour among UCT families that was not the result of error. Simple social interaction with friends and families in the CCT arm may have demonstrated the benefits of additional education. This "spill-over" effect is the result of social interaction rather than contamination.

A programme in Kenya-Cash Transfers for Orphans and Vulnerable Children-builds on this evidence. A paper by the Kenya CT-OVC Evaluation Team notes that expenditure on particular goods changed in unexpected ways among UCT programme families-specifically, expenditure on alcohol, tobacco, food, health, transportation and communication [11]. These families were not required to drink less or spend more money on healthcare, and yet they chose to do so. Did they mistakenly believe they were subject to a condition? It is worth noting that one of the features of many African programmes, including specifically the Kenya programme, is that there is a significant role for the community in the selection of the beneficiaries [11, 
12]. As in the case of Malawi, it is at least possible that it is not a mistaken belief that they were required to abide by conditions in order to access the cash that led families to behave in ways consistent with the conditions. Rather, the community and the interaction of programme families with others may have influenced their behaviour. The communal effects are similarly strong in recent Indian pilots that emphasize UCTs [8].

To summarize more boldly: the condition in a CCT can be characterized as a price effect. Its goal is to encourage "appropriate" behaviour by making it more financially lucrative than it would be without the CCT. The cash transfer in either a CCT or UCT can be characterized as a pure income effect. Individuals have higher incomes but they make decisions about how to spend it based on their own tastes, preferences and circumstances to best meet their own perceived needs. Incentivization is focused on individual decision-making and characterizes social interaction as "contamination" that leads an individual into error. Individuals, however, are social creatures who live in families and communities. They make decisions based on their own best guesses about their own priorities, drawing information from several sources-the programme and programme workers who have power to withhold CTs, as well as families and neighbours who have information and resources upon which they can draw outside the programme, and who have the power to reward or punish behaviour in all kinds of currencies.

\section{The Canadian MINCOME Experiment}

Can we generalize findings from CTs in small villages in sub-Saharan Africa to the BI movement in Europe and North America? Between 1974 and 1979, a Guaranteed Annual Income (GAI) experiment was conducted in Canada. Results were surprisingly consistent with the Malawi results-children stayed in school longer, health was improved and childbearing was delayed, all without the need for researchers to impose conditionality on behaviour. The statistical analyses of the study are presented elsewhere $[4,13]$.

MINCOME was unique among North American negative income tax experiments in that it had two experimental sites, one of which was a saturation site. According to the prevailing wisdom of the time, the Winnipeg site was a classic experiment-representative individuals were selected from the Income Tax Rolls and randomized into experimental and control arms. All lived in the same urban community but, because the proportion of the total population enrolled was small, had little contact with one another. A second site, however, was the town of Dauphin, Manitoba, with a population of approximately 10,000 in the town and another 2,500 in its rural municipality, which served as the saturation site. As in the Malawi experiment, everyone in town was able to participate and received the same offer. In the MINCOME case, trans- fers were means-tested so the offer was that if income fell below a specified threshold, top-ups would be received according to family size and a published formula. No behavioural conditions were imposed.

We were able to exploit a historical accident: universal health insurance (with no private alternative) was introduced into this jurisdiction in 1971. That means that we could access complete population health records for the entire provincial population. We created a comparison group by propensity score matching: every Dauphin resident was matched with three other provincial residents of the same age, sex, family type and community size. We chose comparators from similar geographic and social regions. The only difference between Dauphin residents and the comparators is that the former participated in MINCOME $[4,13]$.

Results were surprisingly large. Hospitalization rates fell $8.5 \%$ for Dauphin residents relative to the comparison group, with "mental health" and "accident and injury" hospitalizations accounting for the biggest drop. We accessed high school enrollment data and discovered that there was a "lucky cohort" of grade 12 students-an unexpected bubble in final year registration exactly coincident with MINCOME.

With no conditionality imposed on behaviour, participants chose to educate their children and behave in ways that reduced poor health. What is surprising about these results, however, is their sheer size. Only $30 \%$ of the families collected a stipend at any point in time, and for many the stipends were very modest. The basic payout for a family with no income from any source was set at $67 \%$ of the low-income cutoff (LICO) which is a relative measure of poverty based on family size and was also approximately what the family might have expected to receive in social assistance. A family of four, for example, would receive $\$ 3,300$, or about $\$ 16,500$ in today's currency. Median family income for a family of 4 was approximately $\$ 11,234$. As income from other sources increased, however, benefits were reduced by $50 \%$ of the additional earnings and disappeared altogether at $120 \%$ of the LICO. What made this programme different from social assistance was the reduction of the threshold effect as families moved off social assistance and into the labour market. The working poor still received some benefits under MINCOME. This design, however, means that many of the $30 \%$ of families who qualified for a stipend actually qualified for very small payments. Outcomes were much larger than anyone should expect them to be, particularly for education. It is easy to imagine why "mental health" should improve if you reduce the stress that is associated with poverty, but why should "accidents and injuries" decline?

When we tried to explain these apparent anomalies, we interviewed participants. We were prevented by the institutional ethics board from contacting participants, but we published stories in the local 
press and used word of mouth to invite people to talk to us. While this strategy no doubt led to some bias in our results, it soon became clear to us how closely people are connected and how the behaviour of one influences another. A seventeen-year old, trying to decide whether to commit to school for another year, will consider (along with his parents) many factors such as the projected income of the family from all sources, including MINCOME. Subjects reported that many of these young men were under considerable pressure before the experiment to become selfsupporting. Could the family afford to support him for another year? Could they do without his income? Was he needed to work on the farm? MINCOME meant that at least some of these vulnerable adolescents were permitted to attend school for another year. From the adolescent's point of view, however, another factor looms large. What would his friends be doing? If MINCOME exists, a greater proportion of his friends will decide to go to school. The more of his friends who attend, the more likely he will attend. That is, the income supplement has both a direct and an indirect effect, the latter resulting from social interaction. Individual decisions are influenced by others, but this is not the result of a mistaken belief that the children were required to attend school in order for the family to receive the stipend. Is this not also a more likely explanation for the proclivity of Malawian girls in the UCT group to go to school, than uncontrolled mingling and "contamination" of information at the payment distribution centre?

What about "accidents and injuries"? Why should they decline? Many hospitalizations with an "accident and injury" code are undeniably social in nature. Violence of all types, including family violence, is associated with poverty and stress. Alcohol abuse and associated automobile accidents are associated with poverty and income insecurity. The less violence and substance abuse exist in a community, the less likely any resident is to be a victim. Both individual behaviour and the behaviour of one's neighbours, family and friends influence the likelihood of these types of hospitalizations. Receiving a cash transfer oneself is protective, but so is the receipt of a cash transfer by others in town.

Most of the people we talked to emphasized the community nature of MINCOME. In the words of one participant:

"It was to bring your income up to where it should be. It was enough to add some cream to the coffee. Everyone was the same so there was no shame" [14].

As was the case for Malawians, the interaction effects in CT schemes are significant. I want to suggest that programmes such as a BI affect social outcomes at levels beyond that of the individual. We are all connected in some very demonstrable and concrete ways. As both the CT experiments in Africa and Latin America and the Canadian MINCOME Experiment suggest, cash transfers do improve investment in human capital. Behaviour does change and development goals are met. What is lacking is a theoretical foundation that explains how they work.

\section{Theory and Design}

It is important to understand how CTs work because the theoretical foundation conditions the optimal design of the programme. A number of issues remain unresolved. Should the programme be universal, or should it be conditional on income or behaviour? Who should be targeted? How large should the transfer be? And, not unrelated to any of the above, how much will it cost? The factors interact with one another and depend on how we imagine a CT to influence behaviour.

Cash transfers to individuals or families have two components. If there is a behavioural condition, the condition works to create incentives that change the mix of goods and services purchased by individuals, usually emphasizing those associated with human capital formation. That is, it becomes financially rewarding for the family to engage in the conditioned behaviour. The cash transfer itself, however, raises family income. How does the income effect influence behaviour?

Consider four theories about how a cash transfer works to change behaviour:

i. CTs work by reducing poverty and increasing income. As income increases, individuals spend less money on some goods and more on normal or luxury goods;

ii. CTs work by reducing risk. A CT is a form of social insurance that increases the planning horizon and allows one to take calculated risks;

iii. CTs work by reducing income inequality, envy and competition;

iv. CTs work by changing social values and building communities through social interaction. Social inclusion is facilitated.

As we move down the list, the focus is less on individual decision-making and more on the interaction of families within a community, but these theories are not mutually exclusive. Does the evidence support any or all of these mechanisms?

\subsection{CTs Work by Reducing Poverty}

Without question, how we spend our income changes as family income increases. Even Maslow recognized that:

"It is quite true that man lives by bread alonewhen there is no bread. But what happens to man's desires when there is plenty of bread and when his belly is chronically filled?" [15]

Manley et al. published a systematic review of 18 programmes in 11 countries to determine the impact 
of CTs and UCTs on nutritional status [16]. They found that if the programme imposed educational or health conditions, nutritional status improved as much as it did in programmes with no conditions. However if conditions related to working and saving were imposed, nutritional status suffered. This review was limited by the fact that CCTs were mostly in the middle-income countries of Latin America and the UCTs in lowerincome African countries, but the finding is telling. Given the freedom to do so, a family will meet its most pressing needs first. An increase in income will be spent on food if food is lacking. As income increases, however, expenditure on food will not continue to increase proportionally. Some inferior goods will be replaced by higher-priced alternatives as resources increase.

What about other decisions? One of the most universal findings is that as income increases, the age of first birth increases and total number of children in a family declines. As income increases, family expenditure on education increases although rarely does expenditure increase equally for all children. Very often, a family will make a rational decision to educate a son rather than a daughter who will leave to go marry into another family. This explains why so many CCTs are focused on the education of girls, but it also explains why more girls are educated in Malawi even in families in the UCT arm. As income increases, the family can afford the luxury of educating its daughters. Even without an incentive-without conditionality -it is easy to understand that what is perceived as an unattainable luxury at one income, such as educating a daughter for someone else, becomes indispensable at a higher income.

Similar, but culturally distinct, findings appeared in the MINCOME study in Canada. As income increased during the experiment, families could afford the luxury of allowing children to remain in school longer. In this case, the luxury was in allowing potentially productive sons to remain in high school; there was relatively well-paying work available to strong young men. Daughters were usually already encouraged to graduate; in the mid-1970s in a small town, their potential employment income was limited. Obviously, context matters but the insight is universal.

The most apparent way that CTs work is by increasing income. Investment in human capital-education and health-will increase with family income. This implies that any CT, with or without a condition, will improve human capital formation if it is large enough. The condition may amplify the result but, as Manley's study demonstrates, a condition might achieve the incentivized outcome by reducing other laudable goals that the family would have chosen given the opportunity [15]. The lesson is clear: conditions are unnecessary for some outcomes. If a condition is to be imposed, it is essential to choose carefully.

Moreover, since expenditure patterns depend on income, it follows that the poorest and most vulnerable families may choose to spend their money differ- ently than those who are better off. UCTs give families the freedom to allocate their income as they choose. If families choose not to meet the condition, either because the incentive is not large enough or because their resources are so constrained that they cannot comply, they will be withdrawn from the study. This has obvious ethical implications, but it also affects costs and cost-effectiveness. CCTs become more economical because non-complying families are not paid. The ultimate cost of the programme will be lower than a comparable UCT that will pay all families.

\subsection{CTs Work by Reducing Risk}

In Canada, support for a BI is overtly compared to universal health insurance and portrayed as a means to reduce risk. It is explicitly characterized as a way of socializing uncertainty and based on the idea that "we are there to help, as members of...a society" [3].

Everyone lives with some economic uncertainty and the further down the income scale you are, the more uncertainty characterizes your life. Many economic decisions affect the future. A decision to send a child to school may involve a commitment of several months. A decision to take a loan to buy a house or a car may involve a commitment of several years. Before the transaction is complete, a job may be lost or health compromised. CTs reduce economic uncertainty. The insurance effect is designed to encourage long-term planning which is the basis of any investment decision, whether in human, social, cultural or physical capital. In the case of human capital formation, it is designed to influence future generations.

The insurance effect, though, goes beyond the individual or the family involved. One of the outstanding design issues is whether CTs should be income-tested. If the design is such that a family receives a stipend only if they qualify for support on the basis of a means test, it will not be universal. It will, however, have an effect on everyone whether or not they qualify for a stipend. It will reduce uncertainty for everyone by setting a minimum beneath which a family income cannot fall. This will have the effect of lengthening the time horizon and allowing a family to undertake some risk even if, in the event, they do not qualify for support.

\subsection{CTs Work Because Income Inequality Is Reduced}

Some poor social outcomes-addictions, crime, poor educational outcomes and chronic health conditionsare distributed across a community, even though they may afflict the poorest most heavily. By definition, income inequality is a social measure. An incometested CT reduces income inequality and will have a differential effect across the income spectrum. Everyone benefits and the poorest, who suffer disproportionately, benefit most.

None of the studies to date has been able to distinguish empirically between an effect that works 
through the reduction of income inequality and one that works through the reduction of absolute poverty.

\subsection{CTs Work by Changing Social Values and Building Community through Social Interaction}

Spillover effects occur when the decisions made by one person or a family affects others. Obvious examples include vaccinations: unvaccinated people benefit from those who choose to vaccinate their children because herd immunity means they are less likely to be infected; education: children attend school when their cousins and neighbours attend school, whether they live in Canada or Malawi. STIs and crime are other examples; both require intimate social interaction.

Spillover effects make CTs extremely cost-effective ways of intervening in society because these effects act like social multipliers: raising your income makes you less likely to abuse illicit substances. I benefit because I am less likely to be the victim of your illegal activities. Raising my income makes my child more likely to finish high school; you benefit because your child will be influenced by the decisions made by my child. Addressing the needs of the poorest means that relatively small investments can have large effects.

CTs can affect the outcomes and behaviours of people who never collect and, under any reasonable forecast, are never likely to collect a stipend either because they have been assigned to a control group or because the stipend is means-tested. They are nonetheless affected, not because of the "contamination" that most of the CT studies acknowledge, but because human interaction changes social attitudes and behavioural norms.

\section{Some Final Thoughts}

Rigorously designed CCTs and, more recently, UCTs have generated a great deal of empirical knowledge about the impact of cash transfers to families in lowand middle-income countries. However, the absence of a well-developed theoretical foundation that attempts to explain how such schemes influence human decision-making means that crucial design questions continue to resonate. Social theory does exist that can be drawn upon to help support the design of CT schemes [17-19]. However, it has not been developed in the context of BI and CT analyses.

Debates about the joint and separate effects of the condition and the cash in generating desired outcomes persist. The role of social interaction remains largely unexplored, beyond appendices attempting to discount the presence of "contamination". The insurance effect remains largely unexplored, which means that the questions of which families ought to be targeted and whether a means-tested scheme might be as effective (and cheaper) than a universal scheme are ignored.

Simultaneously, BI advocates in Europe and North America to a significant extent subsist in a world of theory because there have been no large-scale experiments in high-income countries since the 1970s. Moreover, almost all of the experiments conducted at that time used a dispersed sample which was not capable of detecting the social interaction-the contamination-that seemed to amplify the results of the Canadian MINCOME experiment as it amplified the results of the Zomba experiment in Malawi. This essay has made a tentative step towards integrating these two solitudes.

CTs affect behaviour and outcomes through a variety of mechanisms, and the empirical evidence from CT experiments in Africa and Latin America can offer some guidance to the optimal design of BI schemes in high-income countries. A CCT is a more cost-effective way to encourage outcomes selected by experts than a UCT or BI. Both CCTs and UCTs encourage investment in human capital, but the condition may have an additional impact on encouraging the conditioned behaviour. Both CCTs and UCTs act as social insurance which reduces the risk of forward-looking decisions. As a consequence, both increase investment in human, social, cultural and physical capital, whether or not the behaviour is required as a condition for payment. Any effects of a CT will be magnified by social interaction. The more the decisions of one person affect another, the more effective such a scheme will be.

However, the cost per unit of outcome will be higher with a UCT because a UCT will continue to pay those families who choose not to comply. From a policy perspective, the costs of an unconditional BI (like the costs of any UCT) will exceed those of income support schemes with behavioural conditions attached. If, however, you trust families more than you trust programme designers to choose desirable outcomes, then cash with no strings attached is to be preferred. Both the theory and the empirical results tell us that families can be trusted to allocate their resources where they will achieve the greatest return-whether or not their choices align with the vision of the programme designers. The higher cost of unconditionality is the social price for offering all residents the opportunity to participate fully in society.

\section{Acknowledgements}

The authors are grateful for the generous comments of three referees. Evelyn Forget acknowledges financial support from CIHR (110984). 


\section{References and Notes}

1. A Basic Income (BI) is an income unconditionally granted to all on an individual basis, without means test or work requirement. This is the most common European formulation. A Guaranteed Annual Income (GAI) is a more common variant in North America, and generally refers to a means-tested family income. A negative income tax, or refundable tax credit, is one way of organizing a GAI.

2. Basic Income Earth Network. NewsFlash. Volume 26, no. 69; Spring 2013. Available from: http://www.ba sicincome.org/bien/pdf/Flash69.pdf (accessed on 28 July 2013).

3. Segal H. Scrapping Welfare. The case for guaranteeing all Canadians an income above the poverty line. Literary Review of Canada. 2012;20(10):8-10.

4. Forget EL. The Town With No Poverty: The Health Effects of a Canadian Guaranteed Annual Income Field Experiment. Canadian Public Policy. 2011; 37(3):283-305.

5. Stuckler D, Basu S. The Body Economic. Why Austerity Kills. Toronto, Canada: HarperCollins LTC; 2013.

6. Development Impact Evaluation Initiative. Available from: http://web.worldbank.org/WBSITE/EX TERNAL/EXTDEC/EXTDEVIMPEVAINI/0 , contentMDK:2 2712137 pagePK:64168445 piPK:64168309 theSite PK:3998212,00.html (accessed on 26 July 2013).

7. Gaarder M. Conditional versus unconditional cash: A commentary. Journal of Development Effectiveness. 2012;4(1):130-133.

8. Standing G. The Poor are Responsible Too. Financial Express; 6 June 2013. Available from: http:// www.financialexpress.com/news/column-the-poor-are-r esponsible-too/1125548 (accessed on 29 August 2013).

9. Baird S, McIntosh C, Őzler B. Cash or Condition? Evidence from a Cash Transfer Experiment. Quarterly Journal of Economics. 2011;126(4):1709-1753.

10. Robertson L, Mushati P, Eaton JW, Dumba L, Mavise G, Makoni J, Schumacher C, Crea T, Monasch R,
Sherr L, Garnett GP, Nyamukapa C, Gregson S. Effects of Unconditional and Conditional Cash Transfers on Child Health and Development in Zimbabwe: A cluster randomized trial. Lancet. 2013;381(9874):1283-1292.

11. The Kenya CT-OBC Evaluation Team. The impact of the Kenya Cash Transfer Program for Orphans and Vulnerable Children on household spending. Journal of Development Effectiveness. 2012;4(1):9-37.

12. The Kenya CT-OBC Evaluation Team. The impact of the Kenya Cash Transfer Program for Orphans and Vulnerable Children on human capital. Journal of development effectiveness. 2012;4(1):38-49.

13. Forget EL. New questions, new data, old interventions: The health effects of a guaranteed annual income. Journal of Preventive Medicine. 2013; doi:10. 1016/j.ypmed.2013.05.029.

14. Participants were interviewed in July and August 2011. They remain anonymous in publications.

15. Maslow AH. A Theory of Human Motivation. Psychological Review. 1943;50(4):370-396.

16. Manley J, Gitter S, Slavchevska V. How effective are cash transfer programmes at improving nutritional status? A systematic review of programmes' effects on anthropometric outcomes. Towson University, Department of Economics, Working Paper No. 2010-18. Washington, DC, USA: The World Bank. Available from: http://ideas.repec.org/p/ags/aaea11/103157.html (accessed on 28 July 2013).

17. Durlauf S. Groups, Social Influences, and Inequality: A memberships theory perspective on poverty traps. In: Bowles S, Durlauf S, Hoff K, editors. Poverty Traps. Princeton, NJ, USA: Princeton University Press; 2006. pp. 141-175.

18. Durlauf $S$, Ioannides YM. Social Interactions. Annual Review of Economics. 2010;2(1):451-478. Available from: http://www.annualreviews.org/doi/abs/ 10.1146/annurev.economics.050708.143312 (accessed on 2 September 2013).

19. Glaeser E, Sacerdote B, Scheinkman J. The social multiplier. Journal of the European Economic Association. 2003;1(2-3):345-353. 